\title{
PERBEDAAN SKOR WORK ENGAGEMENT PADA GURU YANG BERSERTIFIKASI DENGAN GURU YANG BELUM BERSERTIFIKASI DI SMP NEGERI SE-KECAMATAN DENPASAR UTARA
}

\author{
Gede Andi Aditya ${ }^{1}$, I Nyoman Adiputra ${ }^{2}$ \\ Program Studi Pendidikan Dokter Fakultas Kedokteran Universitas Udayana ${ }^{1}$ \\ Bagian Ilmu Faal Fakultas Kedokteran Universitas Udayana ${ }^{2}$
}

\begin{abstract}
ABSTRAK
Kinerja optimal guru tercapai apabila guru tersebut telah engaged dengan pekerjaannya. Guru akan merasa tidak terpaksa dalam menjalankan apa yang menjadi tuntutan pekerjaannya bahkan cenderung memberikan lebih dari apa yang menjadi tuntutan pekerjaannya. Kondisi ini merupakan kondisi yang ideal dipertahankan guru dalam menjalankan profesinya. Upaya yang dapat dilakukan agar guru engaged dengan pekerjaannya adalah dengan memberikan suatu pengakuan dan penghargaan. Hal ini dapat dilihat dari salah satu peraturan pemerintah yaitu pelaksanaan sertifikasi guru. Telah dilakukan penelitian observasional dengan pendekatan analitik cross-sectional pada guru di SMP Negeri se-Kecamatan Denpasar Utara dengan jumlah sampel 147 orang. Data dianalisis dengan uji Mann-Whitney dengan tingkat kemaknaan 0,05. Data hasil penelitian diperoleh rata-rata skor work engagement guru yang bersertifikasi adalah $86,23 \pm 8,31$ sedangkan rata-rata skor work engagement guru yang belum bersertifikasi adalah 79,25 $\pm 11,93$. Hasil uji komparabilitas $p=0,003$, menunjukkan bahwa rata-rata skor work engagement antara guru yang bersertifikasi dengan guru yang belum bersertifikasi berbeda secara bermakna $(\mathrm{p}<0,05)$. Dapat dikatakan sertifikasi menjadi salah satu variabel yang berpengaruh terhadap keterikatan kerja (work engagement) guru. Disimpulkan bahwa terdapat perbedaan rata-rata skor work engagement pada guru yang bersertifikasi dengan guru yang belum bersertifikasi dimana skor work engagement guru bersertifikasi lebih tinggi daripada guru belum bersertifikasi. Disarankan untuk dilakukan upaya regulasi oleh pemerintah agar semua guru di Indonesia bersertifikasi.
\end{abstract}

Kata Kunci : Guru, Sertifikasi, Work Engagement 


\title{
DIFFERENCE OF WORK ENGAGEMENT SCORE ON \\ CERTIFIED TEACHER WITH UNCERTIFIED TEACHER AT PUBLIC JUNIOR HIGH SCHOOL IN NORTH DISTRICT OF DENPASAR
}

\begin{abstract}
Optimum performance is achieved when teacher has been engaged with his or her work. Teacher will not feel forced to run his or her job demand and even tend to give more than his or her job demand. These are ideal condition that must be maintained in teacher profession. Efforts to do so teacher engaged with his or her work is to provide an acknowledgment and appreciation. It can be seen from one of the government's regulations implementing teacher certification. Observational studies have been conducted with a cross-sectional analytical approach to the teacher at SMP Negeri in North District of Denpasar with a sample of 147 peoples. Data were analyzed with the Mann-Whitney test with a significance level of 0.05 . Research data obtained an average scores of work engagement on the certified teachers is $86.23 \pm 8,31$ while the average scores of work engagement on uncertified teachers is $79.25 \pm 11,93$. Comparability of test results $p=0.003$, showing that the average scores of work engagement among certified teachers and uncertified teachers significantly different $(\mathrm{p}<0.05)$. It can be said certification is one of the variables that affect the work engagement on teacher. It was concluded that there are differences in the average scores of work engagement on certified teacher with uncertified teacher, where work engagement scores on certified teacher is higher than uncertified teacher. It is recommended for government to certify all teachers in Indonesia.
\end{abstract}

Keyword : Teacher, Certification, Work Engagement

\section{PENDAHULUAN}

Saat ini kualifikasi yang wajib dimiliki oleh seluruh bangsa agar mampu bersaing dalam kompetisi global adalah memiliki sumber daya manusia yang berkualitas, tidak hanya di formal akademis, tetapi juga memiliki pengetahuan dan keahlian dalam bidang tertentu. Hal ini berarti perbaikan segala aspek dan komponen dalam pendidikan menjadi prioritas utama dan salah satunya adalah

keberadaan guru (Ardiansyah, 2013).

Guru berada pada posisi yang strategis bagi seluruh upaya reformasi pendidikan yang berorientasi pada pencapaian kualitas (Ardiansyah, 2013). Kinerja guru yang optimal merupakan modal dasar dalam pengembangan sumber daya manusia Indonesia pada tatanan pendidikan formal. Tugas dan tanggung jawab yang besar menuntut 
seorang guru untuk memberikan mutu

dan kompetensi yang besar agar pendidikan dapat berlangsung dengan baik (Wibowo, dkk., 2010).

Seseorang yang sudah bekerja dapat menampilkan performa kerja yang optimal apabila terlibat dalam pekerjaannya. Tidak terpaksa menjalankan apa yang menjadi tuntutan pekerjaannya dan cenderung memberikan lebih dari apa yang menjadi tuntutan pekerjaannya, hal ini merupakan suatu indikasi bahwa individu tersebut terikat (engaged) dengan pekerjaan (work) nya (Puspita, 2013). Keterikatan kerja (work engagement) merupakan aspek yang meliputi emosi positif, keterlibatan penuh dalam melakukan pekerjaan dan dikarakteristikkan oleh tiga dimensi utama, yaitu semangat (vigor), dedikasi (dedication), serta penyerapan terhadap pekerjaan (absorption) (Schaufeli \& Salanova, 2007). Semangat (vigor) yang didefinisikan sebagai besarnya energi yang digunakan, kemauan untuk memberikan usaha yang bisa dipertimbangkan, tidak gampang menyerah dan menunjukkan ketekunan ketika menghadapi kesulitan. Dedikasi (dedication) merupakan suatu kondisi ketika pekerja mempunyai keterlibatan yang kuat dengan pekerjaannya dan munculnya perasaan tertantang, antusias, dan merasa bahwa pekerjaan yang dilakukannya tersebut dapat memberikan inspirasi yang signifikan bagi dirinya baik secara sosial maupun personal. Penyerapan terhadap pekerjaan (absorption) yang dicirikan oleh penuhnya konsentrasi dan kesenangan hati yang amat sangat sehingga mengalami kesulitan untuk lepas dari pekerjaannya dan merasakan bahwa waktu berlalu sangat cepat selama bekerja (Bakker \& Demerouti, 2008). Tentunya kondisi ini merupakan kondisi ideal yang harus dipertahankan seorang guru dalam menjalankan profesinya. 
Salah satu cara efektif untuk mempertahankan seseorang engaged dengan pekerjaannya adalah bahwa mereka diapresiasi (Hedger, 2007). Kurangnya penghargaan dan pengakuan akan menyebabkan seseorang tidak betah, oleh karena itu pengakuan dan penghargaan merupakan faktor penting bagi engagement (Saks, 2006). Karena itu diperlukan adanya suatu penghargaan maupun pengakuan terhadap guru untuk memperlihatkan bahwa mereka diapresiasi atas kinerja dan pengabdian terhadap profesinya.

Saat ini adanya pengakuan dan penghargaan terhadap guru dapat dilihat dari salah satu peraturan yang dibuat oleh pemerintah yaitu pelaksanaan sertifikasi guru. Undang-Undang Republik Indonesia Nomor 20 Tahun 2003 Bab XVI Pasal 61 ayat (3) menyatakan bahwa sertifikasi merupakan sertifikat kompetensi yang diberikan setelah lulus uji kompetensi oleh satuan pendidikan yang terakreditasi atau lembaga sertifikasi sebagai suatu pengakuan terhadap kompetensi untuk melakukan pekerjaan tertentu. Sebagai penghargaannya pemerintah akan memberikan tunjangan profesi setara gaji pokok (UU No. 14, 2005).

\section{BAHAN DAN METODE}

Penelitian ini merupakan penelitian observasional (noneksperimental) dengan pendekatan analitik cross-sectional untuk mengetahui perbedaan rata-rata skor work engagement pada guru yang bersertifikasi dengan yang belum bersertifikasi di SMP Negeri SeKecamatan Denpasar Utara, yang meliputi SMPN 2 Denpasar, SMPN 3 Denpasar, SMPN 4 Denpasar, SMPN 5 Denpasar, SMPN 10 Denpasar, dan SMPN 12 Denpasar.

Berdasarkan rumus besar sampel (Sastroasmoro \& Ismael, 2008), kriteria inklusi, dan dengan teknik consecutive 
sampling didapatkan sampel untuk penelitian ini sejumlah 147 responden.

Instrumen yang dipakai pada penelitian ini adalah dengan menggunakan kuesioner UWES (Utrecth Work Engagement Scale) untuk mengukur skor work engagement pada guru. Dalam lembar kuesioner terdapat identitas responden, meliputi nama, umur, jenis kelamin, pendidikan terakhir, dan nomor induk pegawai. Kuesioner UWES memiliki 17 pertanyaan yang ditandai dengan tiga aspek, yaitu: kekuatan/vigor (6 pertanyaan), dedikasi/dedication (5 pertanyaan), pengabdian/absorption (6 pertanyaan), dengan pilihan jawaban dari tidak pernah, hampir tidak pernah, jarang, kadang-kadang, sering, sangat sering, dan selalu dengan skor 0 sampai 6. Setelah kuesioner diisi, skor dari masing-masing pertanyaan akan diakumulasi.
Responden yang memenuhi kriteria inklusi diberikan penjelasan tentang manfaat dan tujuan penelitian. Apabila responden bersedia menjadi subjek penelitian, maka diminta menandatangani informed consent dan jika tidak bersedia peneliti tidak memaksa dan akan menghormati hak responden. Responden diberikan lembar kuesioner $U W E S$ untuk mengukur skor work engagement. Data yang telah terkumpul ditabulasi ke dalam program SPSS 20.0 dan dilakukan analisis data.

\section{III.HASIL PENELITIAN}

Dari hasil penelitian didapatkan sejumlah 147 responden, dimana sejumlah 116 responden adalah guru sudah sertifikasi dan 31 responden adalah guru belum sertifikasi. Adapun karakteristik sampel meliputi umur, jenis kelamin, dan latar belakang pendidikan disajikan pada Tabel 1 dan Tabel 
Tabel 1. Distribusi Umur

\begin{tabular}{lllll}
\hline No. & Variabel & Rata-rata & Simpang Baku & Rentangan \\
\hline 1 & Umur & 47,41 & 10,941 & $22-60$ \\
\hline
\end{tabular}

Berdasarkan Tabel 1 didapatkan bahwa variasi umur guru berkisar antara 22-60 tahun dengan rata-rata $47,41 \pm 10,941$ tahun.

Tabel 2. Frekuensi Jenis Kelamin dan Pendidikan

\begin{tabular}{cccc}
\hline & & Frekuensi & Persen \\
\hline \multirow{2}{*}{ Jenis Kelamin } & Laki-laki & 46 & $31 \%$ \\
& Perempuan & 101 & $69 \%$ \\
\hline Pendidikan & D4/S1 & 126 & $86 \%$ \\
& Diatas S1 & 21 & $14 \%$ \\
\hline
\end{tabular}

Berdasarkan Tabel 2 jumlah sampel belakang pendidikan setingkat D4/S1 terbanyak adalah perempuan (69\%) dan sebanyak 86\% dan diatas S1 sebanyak sisanya adalah laki-laki (31\%). Latar 14 $\%$.

Tabel 3. Data Work Engagement Hasil Uji Normalitas

\begin{tabular}{llcc}
\hline Variabel & Sertifikasi & Rerata \pm Simpang & $p^{*}$ \\
& & Baku & \\
\hline Work engagement & Sudah & $86,23 \pm 8,31$ & 0,003 \\
& Belum & $79,25 \pm 11,93$ & 0,160
\end{tabular}

*data berdistribusi normal $\mathrm{p}>0,05$ 
Hasil uji normalitas pada Tabel 3 menunjukkan bahwa nilai $\mathrm{p}$ work engagement pada kelompok sudah sertifikasi adalah 0,003, sedangkan nilai $\mathrm{p}$ work engagement pada kelompok belum sertifikasi adalah 0,160. Karena pada satu kelompok memiliki nilai $\mathrm{p}<$ 0,05, maka dapat disimpulkan bahwa nilai total skor data work engagement tidak berdistribusi normal.

Tabel 4. Hasil Analisis Uji Mann-Whitney

\begin{tabular}{lccc}
\hline & Jumlah Sampel & $\begin{array}{c}\text { Rerata } \pm \text { Simpang } \\
\text { Baku }\end{array}$ & $\mathrm{p}$ \\
\hline $\begin{array}{l}\text { Work engagement guru } \\
\text { bersertifikasi }\end{array}$ & 116 & $86,23 \pm 8,31$ & \\
$\begin{array}{l}\text { Work engagement guru belum } \\
\text { sertifikasi }\end{array}$ & 31 & $79,25 \pm 11,93$ & 0,003 \\
\hline
\end{tabular}

Berdasarkan Tabel 4 diperoleh rata-rata skor work engagement guru bersertifikasi adalah $86,23 \pm 8,31$ dan rata-rata skor work engagement guru yang belum bersertifikasi adalah 79,25 $\pm 11,93$. Karena data tidak berdistribusi normal, uji komparabilitas yang dilakukan dengan uji Mann-Whitney (Dahlan, 2011) dan didapatkan $\mathrm{p}=$ 0,003 .

\section{PEMBAHASAN}

Berdasarkan hasil uji komparabilitas dengan menggunakan uji Mann-Whitney didapatkan rerata skor work engagement guru bersertifikasi adalah 86,23 sedangkan rerata skor work engagement guru belum sertifikasi adalah 79,25 dengan besar koefisien $\mathrm{p}=0,003(\mathrm{p}<0,05)$. Artinya, terdapat perbedaan secara bermakna rerata skor work engagement antara kelompok guru yang 
bersertifikasi dengan kelompok guru yang belum sertifikasi, dimana skor work engagement guru bersertifikasi lebih tinggi daripada guru belum sertifikasi. Hal ini menunjukkan bahwa sertifikasi menjadi salah satu faktor yang menjadikan guru lebih terikat (engaged) dengan pekerjaannya.

Menurut UU Nomor 20 Tahun 2003, sertifikasi merupakan pemberian sertifikat sebagai suatu pengakuan yang diberikan oleh pemerintah kepada guru. Pasal 16 UU Nomor 14 Tahun 2005 tentang guru dan dosen mengatur bahwa guru yang memiliki sertifikat, sebagai penghargaannya pemerintah akan memberikan tunjangan profesi.

Saks (2006) berpendapat bahwa seseorang akan lebih engaged dengan pekerjaannya apabila mereka mendapatkan penghargaan dan pengakuan terhadap performansi mereka. Pengakuan dan penghargaan merupakan faktor penting bagi engagement. Hewitt (dalam Mujiasih \&
Ratnaningsih, 2012) juga mengemukakan bahwa engagement dipengaruhi oleh beberapa faktor, diantaranya adalah penghargaan (total rewards), kondisi perusahaan (company practices), kualitas kehidupan (quality of life), kesempatan (opportunities), aktivitas pekerjaan yang dihadapi (work) dan orang lain di sekitar pekerjaan (people). Keenam hal tersebut berhubungan dengan work engagement yang tinggi.

Dalam model JD-R disebutkan bahwa ada dua hal utama yang mempengaruhi work engagement yaitu job demands dan job resources. Job demands adalah inisiator dari proses perbaikan kesehatan dan job resources adalah inisiator dari proses motivasi. Selama ini hampir sebagian besar studi menunjukkan bahwa job resources lebih penting dalam menentukan work engagement seseorang (HandariAdiputra, 2013), dimana faktor dukungan sosial dalam job resources, 
salah satunya dapat berupa dukungan

penghargaan (Sarafino, 2002).

Penghargaan menurut Ivancevich dkk.

(2007) diklasifikasikan menjadi

kategori ekstrinsik. Pada kategori

ekstrinsik terdapat penghargaan

finansial dan interpersonal.

Penghargaan finansial dapat berupa

gaji, upah, dan tunjangan seperti pusat

penitipan anak, pusat kebugaran, dan

perawatan medis. Penghargaan

interpersonal dapat berupa status dan pengakuan.

Dengan demikian pemberian pengakuan dan penghargaan oleh pemerintah kepada guru, yaitu berupa sertifikasi dapat menjadikan guru lebih engaged dengan pekerjaannya. Adanya tunjangan hidup di hari tua serta imbalan yang lebih tinggi untuk menjaga kualitas kehidupannya, mempengaruhi guru engaged dengan pekerjaannya. Sagala (dalam; Sholihah \& Sholeh, 2013) juga menyebutkan dengan sertifikasi, seorang guru akan meningkatkan kemampuan dan keterlibatannya dalam melaksanakan tugas sebagai guru.

\section{SIMPULAN}

Terdapat perbedaan rata-rata skor work engagement pada guru yang bersertifikasi dengan guru yang belum bersertifikasi dimana skor work engagement guru bersertifikasi lebih tinggi daripada guru belum sertifikasi. Perbedaan ini bermakna signifikan secara statistik, dibuktikan dengan uji Mann-Whitney, $\mathrm{p}<0,05$. Dengan demikian dapat disarankan adanya upaya regulasi oleh pemerintah agar semua guru di Indonesia bersertifikasi. 


\section{DAFTAR PUSTAKA}

Ardiansyah, J. 2013. Peningkatan Kompetensi Guru Bidang Pendidikan di Kabupaten Tana Tidung. e-Journal Pemerintahan Integratif. Vol. 1 (1): 38-50.

Bakker, A. B. \& Demerouti, E. 2008. Towards a model of work engagement. Career development international. Vol. 13 (3): 209-223.

Dahlan, M. S. 2011. Statistik untuk Kedokteran dan Kesehatan. Edisi ke-5. Jakarta: Salemba Medika.

Handari-Adiputra, L. M. I. S. 2013. Ergo-Psikofisiologi Menurunkan Respon Fisiologis, Meningkatkan Kesigapan, Kemampuan Kerja dan Work Engagement Karyawan Bagian Akutansi Hotel Bali Hyatt di Denpasar. (disertasi). Denpasar : Universitas Udayana.

Hedger, A. 2007. Five ways to strengthen your engagement and retention strategies. Workforce Management. 86: 31-37.
Ivancevich, J. M., Robert K., Matteson, M. T. 2007. Perilaku dan Manajemen Organisasi. Jakarta : Erlangga.

Mujiasih, E. \& Ratnaningsih, I. Z. 2012. Meningkatkan Work Engagement Melalui Gaya Kepemimpinan Tranformasional dan Budaya Organisasi. Fakultas Psikologi Universitas Diponegoro.

Puspita, M. D. 2012. Hubungan antara Dukungan Sosial dan Makna Kerja sebagai Panggilan (Calling) dengan Keterikatan Kerja. Calyptra: Jurnal Ilmiah Mahasiswa Universitas Surabaya. Vol. 1 (1).

Saks, A. M. 2006. Antecedents and consequences of employee engagement. Journal of Managerial Psychology. Vol. 21: 600-619.

Sarafino, E. P. 2002. Health Psychology Biopsychosocial Interactions. $4^{\text {th }}$ Ed. United State: John Wiley \& Sons, Inc. 
Sastroasmoro, S. \& Ismael, S. 2011. Dasar - Dasar Metodologi Penelitian Klinis. Edisi ke-4. Jakarta: Sagung Seto.

Schaufeli, W. B., \& Salanova, M. 2007. Work Engagement: An Emerging Psychological Concept and Its Implication for Organizational. Managing Social and Ethical Issues In Organizational. p. 135-177.

Sholihah, R. \& Sholeh, M. 2013. Kompetensi Guru Pasca Sertifikasi di Minu 24 Darussalam Kumalasa
Kecamatan Sangkapura Kabupaten Gresik. Fakultas Ilmu Pendidikan Universitas Negeri Surabaya. Undang-Undang No.14 Tahun 2005. Guru dan Dosen. Yogyakarta: Pustaka Pelajar Offset.

Wibowo, D. M., Ediati, A., Masykur, A. M. 2010. Hubungan antara Kecerdasan Emosi dengan Kinerja Guru SMA Negeri 2 Ngawi. Fakultas Psikologi Universitas Diponegoro.. 